\title{
Whole genome sequencing of penicillin-resistant Streptococcus pneumoniae reveals mutations in penicillin-binding proteins and in a putative iron permease
}

\author{
Fereshteh Fani, Philippe Leprohon, Danielle Légaré and Marc Ouellette
}

\begin{abstract}
Background: Penicillin resistance in Streptococcus pneumoniae is mediated by a mosaic of genes encoding altered penicillin-binding proteins (PBPs). Nonetheless, S. pneumoniae has also developed non-PBP mechanisms implicated in penicillin resistance. In this study, whole genome sequencing of resistant organisms was used to discover mutations implicated in resistance to penicillin.

Results: We sequenced two S. pneumoniae isolates selected for resistance to penicillin in vitro. The analysis of the genome assemblies revealed that six genes were mutated in both mutants. These included three pbp genes, and three non-pbp genes, including a putative iron permease, spr1178. The nonsense mutation in spr1178 always occurred in the first step of the selection process. Although the mutants had increased resistance to penicillin, the introduction of altered versions of PBPs into a penicillin-susceptible strain by sequential transformation led to strains with a minimal increase in resistance, thus implicating other genes in resistance. The introduction by transformation of the non-PBP recurrent mutations did not increase penicillin resistance, but the introduction of the nonsense mutation in the putative iron permease spr1178 led to a reduced accumulation of reactive oxygen species following exposure to penicillin and to other bactericidal antibiotics as well.

Conclusions: This study indicates that the selection of resistance to penicillin in S. pneumoniae involves the acquisition of mutations conferring tolerance to the antibiotic-induced accumulation of oxidants, which translates into an increased survival that putatively enables the selection of major resistance determinants such as mutations in PBPs.
\end{abstract}

\section{Background}

Streptococcus pneumoniae is an important pathogen of the respiratory tract causing community-acquired pneumonia worldwide [1]. It is also an etiological agent of otitis media, sepsis, and meningitis in adults and children and constitutes a significant health threat. Penicillin, a $ß$-lactam antibiotic, has long been the mainstay against pneumococcal infections but its efficacy is threatened by the rapid dissemination of penicillin non-susceptible clones worldwide, the prevalence of which varies between countries (reviewed in $[2,3]$ ).

\footnotetext{
* Correspondence: Marc.Ouellette@crchul.ulaval.ca Centre de recherche en Infectiologie du Centre de recherche du CHUL and Département de Microbiologie, Infectiologie et Immunologie, Faculté de Médecine, Université Laval, 2705 Boul. Laurier, Québec, Canada
}

$\beta$-Lactams are bactericidal antibiotics that inhibit the synthesis of the peptidoglycan layer of bacterial cell walls by inactivating penicillin-binding proteins (PBPs), a group of membrane-associated cytoplasmic proteins involved in the assembly of peptidoglycan and whose inhibition results in growth arrest and lysis. Resistance to ß-lactam antibiotics in clinical isolates of S. pneumoniae occurs through the acquisition of mosaic genes encoding altered PBPs. The mosaic genes encode PBP variants of lower antibiotic binding affinities and are the result of intra- and interspecies gene transfer events involving related streptococcal species [4,5]. Although $S$. pneumoniae contains six PBPs, variants of PBP2x, $\mathrm{PBP} 2 \mathrm{~b}$ and PBP1a are considered the most relevant to penicillin resistance. Furthermore, the acquisition of
() Biomed Central

(c) 2011 Fani et al.; licensee BioMed Central Ltd. This is an open access article distributed under the terms of the Creative Commons Attribution License (http://creativecommons.org/licenses/by/2.0), which permits unrestricted use, distribution, and reproduction in any medium, provided the original work is properly cited. 
low-affinity $\mathrm{PBP} 2 \mathrm{x}$ and $\mathrm{PBP} 2 \mathrm{~b}$ variants was shown to be a prerequisite for $\mathrm{PBP} 1 \mathrm{a}$ variants to confer high-level resistance to $ß$-lactams [6,7]. PBP2x has the highest affinity for penicillin in S. pneumoniae and a variety of amino acid substitutions interfering with the polarity and charge distribution in the vicinity of the active site have been implicated in poor antibiotic binding and resistance $[8,9]$.

Mutations in PBPs are not the sole contributors of resistance to ß-lactams in S. pneumoniae, and evidence for some non-PBP resistance mechanisms is available. Indeed, the cell wall of penicillin non-susceptible isolates is often highly enriched in branched chain muropeptides, a phenomenon linked to mosaic alleles of the murM gene $[10,11]$. Furthermore, mutations in a peptidoglycan $\mathrm{N}$-acetylglucosamine deacetylase [12], a peptidoglycan O-acetyltransferase [13], a putative glycosyltransferase [14], a serine threonine kinase [15], a histidine protein kinase part of a two-component signal transducing system [16], or in a phosphate ABC transporter [17] have been implicated in resistance to $B$ lactams.

Global approaches such as whole genome sequencing (WGS) of antibiotic-sensitive and -resistant isolates are powerful tools that are now readily available for use in determining the mode of action of antimicrobial drugs and the mechanisms involved in resistance [18-20]. We report here the WGS of two independent S. pneumoniae mutants selected for in vitro resistance to penicillin and the identification of known and new mutations involved in resistance.

\section{Results}

Selection and whole-genome sequencing of $S$. pneumoniae penicillin non-susceptible mutants

Two independent penicillin-resistant mutants of $S$. pneumoniae R6 and S. pneumoniae 1974 were selected by stepwise penicillin increments until they reached a final penicillin minimum inhibitory concentration (MIC) of $2 \mu \mathrm{g} / \mathrm{ml}$. It has not been possible to obtain mutants resistant to higher levels. The penicillin MICs of the wild-type (WT) progenitors were $0.023 \mu \mathrm{g} / \mathrm{ml}$ and 0.016 $\mu \mathrm{g} / \mathrm{ml}$ for the S. pneumoniae R6 and 1974 lineages, respectively. The most highly resistant isolates were named R6M1 and R6M2 or 1974M1 and 1974M2 depending on whether they were derived from the $S$. pneumoniae R6 or 1974 background, respectively. All four penicillin-resistant strains were cross resistant to the cefotaxime but remained susceptible to erythromycin, tetracycline, linezolid, kanamycin and ciprofloxacin (Table 1).

We conducted WGS of R6M1 and R6M2 in order to elucidate the genetic events associated with the penicillin-resistant phenotype. The genome of R6M1 was
Table 1 Susceptibility levels of S.pneumoniae isolates

\begin{tabular}{lccccccc}
\hline $\begin{array}{l}\text { S. pneumoniae } \\
\text { strain }\end{array}$ & PG & CT & EM & Cl & KM & TC & LZ \\
\hline R6-WT & 0.023 & 0.023 & 0.125 & 0.5 & 25 & 0.125 & 0.38 \\
R6M1 & 2.0 & 0.75 & 0.125 & 0.5 & 25 & 0.125 & 0.38 \\
R6M2 & 2.0 & 0.75 & 0.125 & 0.5 & 25 & 0.125 & 0.38 \\
$1974-W T$ & 0.016 & 0.023 & 0.125 & 0.5 & 25 & 0.125 & 0.75 \\
$1974 M 1$ & 2.0 & 1.5 & 0.125 & 0.5 & 25 & 0.125 & 0.75 \\
$1974 M 2$ & 2.0 & 2.0 & 0.125 & 0.5 & 25 & 0.125 & 0.75 \\
\hline
\end{tabular}

Results are the average of at least three independent measurements. $\mathrm{Cl}$, ciprofloxacin; $C T$, cefotaxime; $E M$, erythromycin; $K M$, kanamycin; $L Z$, linezolid; PG, penicillin G; TC, tetracycline; WT, wild-type.

sequenced by using the comparative genome sequencing technology developed by NimbleGen, which relies on the use of tiled DNA microarray hybridizations to rapidly survey entire microbial genomes and to identify the location of SNPs, insertions, or deletions $[19,20]$. The comparative genome sequencing of R6M1 and WT parent allowed the identification of 26 mutations in R6M1 (Table 2) that were further confirmed by PCR amplification and conventional DNA sequencing. The genome of R6M2 was sequenced using the massively parallel 454 Life Science (Roche) GS-FLX DNA sequencing platform, which generated a genome assembly of $28 \times$ coverage, with $97 \%$ of the reads assembled into 78 large contigs. Comparative sequence analysis of R6M2 and its R6 WT parent revealed 52 mutations (Table 2) that were confirmed by PCR amplification and conventional DNA sequencing. The mutations can also be seen as part of circular schematic maps (Additional file 1).

The WGS of R6M1 and R6M2 identified a total of 40 genes that have acquired a non-synonymous mutation in at least one of the mutants (Table 2). Of these, six genes were mutated in both mutants (Table 3 ). These included three PBP-encoding genes, $p b p 2 x, p b p 2 b$ and $p b p 1 a$, in which a total of 14 missense mutations and one nonsense mutation have been observed in R6M1 and R6M2 (Table 3). The targeted sequencing of the six common genes in the 1974M1 and 1974M2 strains identified another 14 missense substitutions in PBP2x and PBP2b and nonsense mutations in PBP1a (Table 3). The T451A and G435S amino acid substitutions in PBP2b and the R384G, V518I and Q552E substitutions in PBP2x were shared by some of the mutants derived from R6 and 1974 (Table 3). The three other non-PBPencoding genes identified by WGS mutated in both R6 mutants (although not always at the same position) were the ABC protein PstB (spr1254), the DNA mismatch repair protein HexA (spr1888) and a hypothetical protein (spr1178). Interestingly, the analysis of targeted PCR fragments from 1974M1 and 1974M2 revealed that the same nonsense mutation occurred at position 28 of the spr1178 protein in all mutants but no mutations 
Table 2 Mutations identified in R6M1 and R6M2 penicillin-resistant mutants

\begin{tabular}{|c|c|c|c|c|c|}
\hline \multirow[b]{3}{*}{$\begin{array}{l}\text { Locus } \\
\text { name }\end{array}$} & \multirow[b]{3}{*}{ Putative identification } & \multicolumn{4}{|c|}{ S. pneumoniae strain } \\
\hline & & \multicolumn{2}{|c|}{ M1 } & \multicolumn{2}{|c|}{ M2 } \\
\hline & & $\begin{array}{l}\text { Nucleotide } \\
\text { change }\end{array}$ & $\begin{array}{l}\text { Amino acid } \\
\text { change }\end{array}$ & $\begin{array}{l}\text { Nucleotide } \\
\text { change }\end{array}$ & $\begin{array}{l}\text { Amino acid } \\
\text { change }\end{array}$ \\
\hline spr0032 & DNA polymerase I & & & A107G & H36R \\
\hline \multirow[t]{4}{*}{ spr0041 } & Transposase (orf2) & & & GAA31AAC & E11N \\
\hline & & & & GCTCG36TCTCA & $\mathrm{K} 12 \mathrm{~N} ; \mathrm{D} 14 \mathrm{~N}$ \\
\hline & & & & T63A & SYN \\
\hline & & & & GG204TA & D69Y \\
\hline spr0113 & Hypothetical protein & & & A4G & $\mathrm{K} 2 \mathrm{E}$ \\
\hline \multirow[t]{2}{*}{ spr0121 } & Surface protein PspA precursor & & & $\mathrm{A} 4 \mathrm{G}$ & $\mathrm{N} 2 \mathrm{D}$ \\
\hline & & & & T1374C & SYN \\
\hline spr0160 & DNA mismatch repair protein (Hex B) & & & G752A & $\mathrm{S} 251 \mathrm{~N}$ \\
\hline spr0182 & Hypothetical protein & & & G82insertion & frame shift \\
\hline spr0284 & Alpha-xylosidase & & & T1107C & SYN \\
\hline \multirow[t]{5}{*}{ spr0304 } & Penicillin-binding protein $2 x$ & A1150G & R384G & A842C & Q281P \\
\hline & & G1552T & V518L & C1106T & A369V \\
\hline & & C1654G & Q552E & A1150G & R384G \\
\hline & & & & $\mathrm{C} 1276 \mathrm{~T}$ & R426C \\
\hline & & & & G1552A & V5181 \\
\hline spr0329 & Penicillin-binding protein 1a & G1630A & G544R & G1233A & W411* \\
\hline spr0376 & Conserved hypothetical protein & & & T207C & SYN \\
\hline spr0422 & Hypothetical protein & & & C391T & Q131* \\
\hline spr0475 & Conserved hypothetical protein & G318C & L106F & & \\
\hline spr0509 & Phenylalanyl-tRNA synthetase beta chain & & & C105T & SYN \\
\hline spr0598 & $\begin{array}{l}\text { GTP-binding protein (TypA/BipA) (tyrosine phosphorylated } \\
\text { protein A) }\end{array}$ & & & C905T & P302L \\
\hline spr0666 & ABC transporter ATP-binding protein - cell division (FtsE) & C410T & P137L & & \\
\hline spr0764 & 30S Ribosomal protein S1 & & & G1173A & M391। \\
\hline spr0776 & D-Alanyl-D-alanine carboxypeptidase & & & C287T & A96V \\
\hline spr0866 & Dihydroorotate dehydrogenase & C575T & P192L & & \\
\hline spr0878 & Exoribonuclease $\mathrm{R}$ & G280T & G94W & & \\
\hline spr0895 & Conserved hypothetical protein & & & G134C & R45T \\
\hline spr0917 & Citrulline cluster-linked gene & С59T & A20V & & \\
\hline spr0934 & $\mathrm{ABC}$ transporter substrate-binding protein - iron transport & & & G486A & W162* \\
\hline spr1041 & Hypothetical protein & C648T & SYN & & \\
\hline spr1043 & Conserved hypothetical protein & C109T & P37S & C105T & SYN \\
\hline spr1092 & tRNA pseudouridine $5 \mathrm{~S}$ synthase & & & C210T & SYN \\
\hline spr1127 & Ribonuclease III & A228G & SYN & C554T & T1851 \\
\hline spr1152 & LicD & G692T & P231L & & \\
\hline spr1166 & Signal recognition particle (Fifty four homolog) & C139T & P47S & & \\
\hline spr1178 & Hypothetical protein & $\mathrm{C} 82 \mathrm{~T}$ & Q28* & C82T & Q28* \\
\hline \multirow[t]{5}{*}{ spr1186 } & N-Acetylneuraminate lyase subunit, truncation & & & T603C & SYN \\
\hline & & & & G620A & G207D \\
\hline & & & & GAC660AAT & T2211 \\
\hline & & & & AA689CG & E230A \\
\hline & & & & T696A & SYN \\
\hline spr1224 & Conserved hypothetical protein & & & T564C & SYN \\
\hline spr1240 & Alanyl-tRNA synthetase & & & A139G & T47A \\
\hline spr1254 & $\begin{array}{l}\text { ABC transporter ATP-binding protein-phosphate transport } \\
(\text { PstB) }\end{array}$ & G499A & G167S & C614T & T2051 \\
\hline spr1260 & Conserved hypothetical protein & & & T597C & SYN \\
\hline spr1272 & N-Acetylglucosamine-6-phosphate isomerase & G385A & G129R & & \\
\hline
\end{tabular}


Table 2 Mutations identified in R6M1 and R6M2 penicillin-resistant mutants (Continued)

\begin{tabular}{|c|c|c|c|c|c|}
\hline spr1384 & UDP-N-acetylmuramoyl-L-alanyl-D-glutamyl-L-lysine ligase & G996A & M332I & & \\
\hline spr1423 & Conserved hypothetical protein & & & A673G & M225V \\
\hline spr1453 & Major facilitator superfamily transporter & T91C & F31L & & \\
\hline spr1465 & Conserved hypothetical protein & G419A & G140E & & \\
\hline \multirow[t]{3}{*}{ spr1517 } & Penicillin-binding protein $2 \mathrm{~b}$ & C1245A & D415E & C1184T & A395V \\
\hline & & C1528A & G665D & G1303A & G435S \\
\hline & & & & A1351G & $\mathrm{T} 451 \mathrm{~A}$ \\
\hline spr1587 & Conserved hypothetical protein & C568T & SYN & & \\
\hline spr1703 & ABC transporter ATP-binding protein - oligopeptide transport & C575A & P192Q & & \\
\hline spr1706 & $\begin{array}{l}\text { ABC transporter membrane-spanning permease - } \\
\text { oligopeptide transport }\end{array}$ & & & T399deletion & frameshift \\
\hline spr1862 & Competence protein & & & A51G & SYN \\
\hline spr1886 & Degenerate transposase & A314G & $* 105 \mathrm{~W}$ & & \\
\hline spr1888 & DNA mismatch repair protein (HexA) & C2183T & T7281 & C976T & Q326* \\
\hline spr1991 & Glycerol kinase & & & GG78TT & $\mathrm{E} 27^{*}$ \\
\hline
\end{tabular}

Asterisks and SYN indicate nonsense mutations and synonymous mutations, respectively.

were seen in spr1254 and spr1888 in the 1974 mutants (Table 3).

\section{Reconstruction of resistance by transformation of mutated PBPs}

Transformation experiments of S. pneumoniae R6 WT with $p b p$ genes amplified from either the R6M1 or R6M2 mutants were conducted to assess the contribution of the different PBP mutations to penicillin resistance. The analysis of the PBP sequences at the different levels of R6M1 and R6M2 selection (0.06, 0.125, 0.25, $0.5,1.0$ and $2.0 \mu \mathrm{g} / \mathrm{ml}$ penicillin $\mathrm{G}(\mathrm{PG})$ ) revealed a stepwise selection of PBP mutations (Additional file 2). The analysis of the chronological appearance of PBP mutations in R6M2 revealed that the progression towards penicillin resistance began with the Q281P substitution in PBP2x followed by the T451A substitution in PBP2b. The other PBP2x mutations happened sequentially as the level of resistance to penicillin increased and the remaining $\mathrm{PBP} 2 \mathrm{~b}$ and $\mathrm{PBP} 1 \mathrm{a}$ mutations were only selected at high concentration of penicillin (Additional file 2). The $p b p 2 x, p b p 2 b$ and $p b p 1 a$ genes were amplified from R6M1 and R6M2 genomic DNA and were sequenced to confirm the presence of the mutations described in Table 3. Because of the order of mutation appearance (Additional file 2), we introduced sequentially the R6M1 mutations by first transforming the PCR fragment for $p b p 2 x$ into the recipient S. pneumoniae R6 WT. The selection of transformants with $0.03 \mu \mathrm{g} / \mathrm{ml}$ penicillin enabled the transfer of the three PBP2x mutations found in R6M1 (R384G, V518L, Q552E). This transformant, named $\mathrm{R} 6^{2 \mathrm{x}-\mathrm{M} 1}$, had a penicillin MIC of $0.06 \mu \mathrm{g} / \mathrm{ml}$ (Table 4). In a second round of transformation, the $p b p 2 b$ gene from R6M1 was used as donor DNA for the transformation of the recipient $R 6^{2 x-M 1}$. Selection with $0.06 \mu \mathrm{g} / \mathrm{ml}$ penicillin yielded second-level transformants that acquired the two PBP2b mutations of R6M1 (D415E, G665D) and these transformants, called $R 6^{2 \times 2 b-M 1}$, had a penicillin MIC of $0.125 \mu \mathrm{g} / \mathrm{ml}$ (Table 4). All attempts to introduce pbp1a mutations failed. We used a similar approach for R6M2 but in the first level transformation we pooled the $p b p 2 x, 2 b$ and 1a PCR fragments derived from R6M2 that were transformed into R6WT. The selection of transformants with $0.03 \mu \mathrm{g} / \mathrm{ml}$ penicillin enabled the transfer of only the PBP2x mutations Q281P, A369V and R384G, but not

Table 3 Genes mutated in at least two S.pneumoniae penicillin resistant mutants

\begin{tabular}{lllll}
\hline & & \multicolumn{2}{c}{ S. pneumoniae strains } \\
Locus name & R6M1 & R6M2 & 1974M1 & 1974M2 \\
\hline PBP1a & G544R & W411* & E248* & E158* \\
PBP2x & R384G,V518I, Q552E & Q281P, A369V, R384G, R426C, V518I & F388L, Q552E, V573L, V587L, G601V & A507V, P535L, Q552E \\
PBP2b & D415E, G665D & A395V, G435S, T451A & G435S, T451A & T431D, T451A, L492F, Q633E \\
Spr1178 & Q28* & Q28* & Q28* & Q28* \\
Spr1254 & G1675 & T2051 & WT & WT \\
Spr1888 & T728l & Q326* & WT & WT \\
\hline
\end{tabular}

Mutations are shown as amino acid changes with their corresponding position in the protein. Asterisks indicate nonsense mutations. Mutations that are common in at least two strains are in bold. 
Table 4 Minimal inhibitory concentrations to penicillin of Streptococcus pneumoniae mutants and transformants

\begin{tabular}{|c|c|c|}
\hline $\begin{array}{l}\text { Strain or } \\
\text { transformant }\end{array}$ & Description & $\begin{array}{l}\text { MIC to PG } \\
(\mu \mathrm{g} / \mathrm{ml})^{\mathrm{a}}\end{array}$ \\
\hline R6 & Wild type & 0.023 \\
\hline CCRI1974 & S. pneumoniae, sensitive clinical isolate & 0.023 \\
\hline R6M1 & R6 clone selected in vitro for PG resistance & 2.0 \\
\hline $\mathrm{R} 6 \mathrm{M} 2$ & R6 clone selected in vitro for PG resistance & 2.0 \\
\hline 1974M1 & 1974 clone selected in vitro for PG resistance & 2.0 \\
\hline $1974 \mathrm{M} 2$ & 1974 clone selected in vitro for PG resistance & 2.0 \\
\hline CP1250 & S. pneumoniae that contains a spontaneous mutation in the rps $L$ gene that confers resistance to SM & \\
\hline$R 6^{2 x-M 1}$ & $\begin{array}{l}\text { R6-WT transformed with pbp2x PCR fragments from R6M1 (contains all three missense mutations present in } \\
\text { PBP2x of R6M1) }\end{array}$ & 0.06 \\
\hline$R 6^{2 x-M 2}$ & $\begin{array}{l}\text { R6-WT transformed with pbp2x PCR fragments from R6M2 (contains just three mutations - Q281P, A369V, R384G } \\
\text { - out of five mutations present in PBP2x of R6M2) }\end{array}$ & 0.06 \\
\hline$R 6^{2 \times 2 b-M 1}$ & $\begin{array}{l}\mathrm{R} 6^{2 \mathrm{x}-\mathrm{M} 1} \text { transformed with pbp } 2 b \mathrm{PCR} \text { fragments from } \mathrm{R} 6 \mathrm{M} 1 \text { so all missense mutations present in PBP2b of R6M1 } \\
\text { transformed into this transformant }\end{array}$ & 0.125 \\
\hline$R 6^{2 \times 2 b-M 2}$ & $\begin{array}{l}\mathrm{R}^{2 \mathrm{x}-\mathrm{M} 2} \text { transformed with pbp } 2 \mathrm{~b} P C R \text { fragments from } \mathrm{R} 6 \mathrm{M} 2 \text { so all missense mutations present in } \mathrm{PBP} 2 \mathrm{~b} \text { of } \mathrm{R} 6 \mathrm{M} 2 \\
\text { transformed into this transformant }\end{array}$ & 0.125 \\
\hline $\mathrm{R}^{2 \times 2 \mathrm{~b}-\mathrm{M} 2,1 \mathrm{a}: J a n u s}$ & $\mathrm{R} 6^{2 \times 2 \mathrm{~b}-\mathrm{M} 2}$ knocked out in pbpla by Janus cassette, $\mathrm{KM}^{\mathrm{R}} \mathrm{SM}^{\mathrm{S}}$ & 0.125 \\
\hline$R 6^{\mathrm{SmR}, 2 \times 2 \mathrm{~b} 1 \mathrm{a}-\mathrm{M} 2}$ & $\begin{array}{l}R 6^{2 \times 2 b-M 2, ~ 1 a: J a n u s ~ s u b j e c t e d ~ t o ~ s e c o n d ~ s t e p ~ t r a n s f o r m a t i o n ~ w i t h ~ p b p l a ~ o f ~ t h e ~ J a n u s ~ c a s s e t t e ~ w i t h ~ p b p l a ~ o f ~} \\
\mathrm{R} 6 \mathrm{M} 2, \mathrm{KM}^{\mathrm{S}} \mathrm{SM}^{\mathrm{R}}\end{array}$ & 0.125 \\
\hline $\begin{array}{l}\mathrm{R}_{6}^{\mathrm{SmR}, 2 \times 2 \mathrm{~b} 1 \mathrm{a},} \\
\text { spr1178-M2, }\end{array}$ & $\begin{array}{l}\text { R6 } 2 \times 2 \mathrm{~b} 1 \mathrm{a}-\mathrm{M} 2 \text { transformed with spr1178 PCR fragments from R6M2 (contains a Q28* nonsense mutation in } \\
\text { spr1178), SM }\end{array}$ & 0.125 \\
\hline $\mathrm{R} 6^{2 \times 2 \mathrm{~b}, \mathrm{sp} r 1254-\mathrm{M} 2}$ & $\mathrm{R}^{2 \times 2 \mathrm{~b}-\mathrm{M} 2}$ transformed with pstB PCR fragment from R6M2 (contains a T205I mutation in PstB) & 0.125 \\
\hline $\begin{array}{l}\mathrm{R}^{2 \times 2 \mathrm{~b}, \mathrm{spr} 1254} \\
\mathrm{spr} 1178-\mathrm{M} 2\end{array}$ & $\begin{array}{l}\text { R6 } 2 \times 2 \mathrm{~b}-\mathrm{M} 2 \text { transformed with spr1178 and pstB PCR fragments from R6M2 (contains the substitutions Q28* in } \\
\text { spr1178 and T205I in PstB) }\end{array}$ & 0.125 \\
\hline $\mathrm{R} 6 \mathrm{M} 1^{\mathrm{SmR}, 1 \mathrm{a}-\mathrm{WT}}$ & R6M1 co-transformed with a pbpla PCR fragment from R6-WT and a rps $L$ streptomycin resistance marker, SM ${ }^{R}$ & 1.0 \\
\hline $\mathrm{R}^{\mathrm{ko}}$ in spr1178 & R6-WT knocked out in spr1178, $\mathrm{CM}^{R}$ & 0.023 \\
\hline$R 6^{\mathrm{ko}}$ in spr1254 & R6-WT knocked out in spr1254, KM ${ }^{R}$ & 0.023 \\
\hline R6 $6^{\text {spr1888:janus }}$ & R6-WT knocked out in spr1888 by Janus cassette, $\mathrm{KM}^{\mathrm{R}} \mathrm{SM}^{\mathrm{S}}$ & 0.023 \\
\hline
\end{tabular}

Results are the average of at least three independent measurements. Asterisks indicate nonsense mutations. PG, penicillin; KM, kanamycin; SM, streptomycin.

the R426C and V518I mutations despite several attempts. The transformants, named $\mathrm{R} 6^{2 \mathrm{x}-\mathrm{M} 2}$, had a penicillin MIC of $0.06 \mu \mathrm{g} / \mathrm{ml}$ (Table 4). In a second round of transformation, a pool of $p b p 2 b$ and $p b p 1 a$ PCR fragments from R6M2 was used as donor DNA in the transformation of the recipient $\mathrm{R} 6^{2 \mathrm{x}-\mathrm{M} 2}$. Selection with $0.06 \mu \mathrm{g} / \mathrm{ml}$ penicillin yielded second-level transformants that acquired the three PBP2b mutations of R6M2 (T451A, G435S and A395V) but retained an unaltered allele of pbp1a. These transformants, named $\mathrm{R}^{2 \times 2 \mathrm{~b}-\mathrm{M} 2}$, had a penicillin MIC of $0.125 \mu \mathrm{g} / \mathrm{ml}$ (Table 4). Several attempts failed to introduce the PBP1a mutation of R6M2 into the $\mathrm{R}^{2 \times 2 \mathrm{~b}-\mathrm{M} 2}$ line.

Given that PBP1a variants are usually associated with high level $\beta$-lactam resistance, we assessed the role of the R6M2 pbp1a point mutation by transforming the $\mathrm{R}^{2 \times 2 \mathrm{~b}-}$ ${ }^{\text {M2 }}$ line with the rpsL Janus cassette [21]. This required the introduction of a mutated rpsL gene to obtain a R6 transformed cell resistant to streptomycin (see Materials and methods). The integration of the PBP1a Janus cassette (Additional file 3) into an $\mathrm{R} 6^{2 \times 2 \mathrm{~b}-\mathrm{M} 2}$ streptomycinresistant recipient $\left(\mathrm{R} 6^{\mathrm{SmR}, 2 \times 2 \mathrm{~b}-\mathrm{M} 2}\right)$ was selected under kanamycin pressure and yielded streptomycin-sensitive and kanamycin-resistant $\mathrm{R} 6^{2 \times 2 \mathrm{~b}-\mathrm{M} 2 \text {, 1a::janus }}$ transformants. The replacement of the Janus cassette from $R 6^{2 \times 2 b-M 2, ~ 1 a:: ~}$ janus was performed in a second round of transformation with a $p b p 1 a$ fragment amplified from R6M2 flanked by $3 \mathrm{~kb}$ of upstream and downstream regions (Additional files 3 and 4). The selection under streptomycin pressure yielded the streptomycin-resistant and kanamycin-sensitive $\mathrm{R} 6^{\mathrm{SmR}, 2 \times 2 \mathrm{~b} 1 \mathrm{a}-\mathrm{M} 2}$ transformants that acquired the pbp1a allele of R6M2. However, although the targeted sequencing of $p b p 1 a$ in $\mathrm{R}^{\mathrm{SmR}, 2 \times 2 \mathrm{~b} 1 \mathrm{a}-\mathrm{M} 2}$ confirmed the acquisition of the R6M2 nonsense mutation at position 411 of the protein, this strain had penicillin resistance levels identical to those of the $\mathrm{R}^{2 \mathrm{x} 2 \mathrm{~b}-\mathrm{M} 2}$ line (MIC 0.125 $\mu \mathrm{g} / \mathrm{ml}$; Table 4). We tested further the role of PBP1a in resistance by introducing a wild-type copy of the gene in the penicillin-resistant mutant R6M1. The co-transformation of a pbpla fragment amplified from S. pneumoniae R6 WT with a rpsL fragment conferring streptomycin resistance into R6M1 yielded the R6M1 ${ }^{\text {SmR,1a-wt }}$ transformant that harbored a WT pbp1a allele. Interestingly, the R6M1 ${ }^{\mathrm{SmR}, 1 \mathrm{a}-\mathrm{wt}}$ transformant became two times more sensitive to penicillin (PG MIC $1.0 \mu \mathrm{g} / \mathrm{ml}$ ) than its parent (Table 4). 


\section{The inactivation of spr1178 confers tolerance to antibiotic-induced oxidants}

In addition to the mutations in $p b p$ genes, the WGS highlighted three genes that were mutated in both the R6M1 and R6M2 mutants (spr1178, spr1254 and spr1888) but only spr1178 was also mutated in 1974M1 and 1974M2. Although an increased expression of the PstB ABC transporter subunit (spr1254) had previously been associated with penicillin resistance [17], its inactivation by insertional duplication mutagenesis in S. pneumoniae R6 WT did not translate into increased penicillin tolerance (Table 4). Similarly, the independent inactivation of spr1178 or spr1888 in a WT background had no effect on the level of penicillin susceptibility (Table 4). Given that the nonsense mutation in spr1178 had been acquired in every penicillin-resistant mutant analyzed, we tested whether this recurrence required a background of altered PBPs in order to confer resistance. Again, neither the independent transformation of the mutated versions of spr1178 and spr1254 into $\mathrm{R}^{\mathrm{SmR}, 2 \times 2 \mathrm{bla}-\mathrm{M} 2}$ and $\mathrm{R} 6^{2 \times 2 \mathrm{~b}-\mathrm{M} 2}$ recipients nor the simultaneous transformation of the spr1178 and spr1254 mutations into an $\mathrm{R} 6^{2 \times 2 \mathrm{~b}-\mathrm{M} 2}$ recipient altered the penicillin susceptibility of the transformants (Table 4).

Spr1178 encodes a protein of 192 amino acids with one predicted transmembrane domain that was categorized as part of the DUF3347 family of functionally uncharacterized proteins by Pfam analysis. However, a BLAST analysis for spr1178 homologues in different Streptococcus species revealed several proteins annotated as $\mathrm{Fe}^{2+} / \mathrm{Pb}^{2+}$ permeases with at least $70 \%$ identity. Indeed, spr1178 had $86.9 \%$ and $86.7 \%$ similarity with a putative iron permease of the FTR1 family [22] from Streptococcus gordonii [23] and Streptococcus mitis ATCC6249, respectively, and 94\% identity with a putative high-affinity $\mathrm{Fe}^{2+} / \mathrm{Pb}^{2+}$ permease from $S$. pneumoniae 670-6B, S. pneumoniae CDC3059-06 and S. pneumoniae P1031. Intriguingly, the bactericidal activity of antibiotics like $\beta$-lactams has recently been linked to the iron-dependent accumulation of reactive oxygen species (ROS) [24]. Since spr1178 has a predicted iron permease function, we sought to determine whether the acquisition of the nonsense mutation in spr1178 could translate into decreased accumulation of ROS following exposure to penicillin. Using the dichlorofluorescein diacetate (DCF-DA) dye, whose fluorescence intensity is proportional to the levels of ROS, we showed that subinhibitory concentrations of penicillin induced a greater time-dependent increase in ROS accumulation in a $S$. pneumoniae $\mathrm{R}^{\mathrm{SmR}}{ }^{\mathrm{S}}$ 2x2b1a-M2 background than in cells in which the spr1178 nonsense mutation was introduced (Figure 1a). Similarly, penicillin induced a greater accumulation of ROS in R6 WT in comparison to a R6 WT strain in which spr1178 was disrupted (data not shown).
We next tested whether this was a more general feature of bactericidal antibiotics and we found that ciprofloxacin (Figure 1b) and kanamycin (Figure 1c) also induced significantly more ROS in cells harboring an unaltered spr1178 gene. The time-dependent accumulation of ROS was a specific feature of bactericidal antibiotics, since the bacteriostatic antibiotics chloramphenicol (Figure 1d) and tetracycline (Figure 1e), respectively, failed to induce ROS even in the presence of a WT version of spr1178 and only induced a slight accumulation of ROS that was not correlated to the functional status of spr1178.

Growth kinetics revealed that penicillin resistance conferred a fitness cost to R6M1 (Figure 2b) and R6M2 (data not shown). The acquisition of PBP2x, $2 \mathrm{~b}$ and $1 \mathrm{a}$ mutations was not associated with this growth defect, as

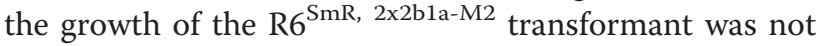
altered compared to S. pneumoniae R6 WT (Figure 2a). In contrast, the introduction of a nonsense mutation in spr1178 conferred a fitness cost, as the growth of the

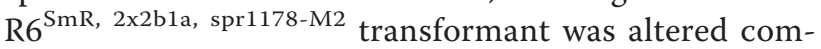
pared to its $\mathrm{R} 6^{\mathrm{SmR}, 2 \times 2 \mathrm{bla}-\mathrm{M} 2}$ parent or to $S$. pneumonaie R6 WT (Figure 2a). Similarly, the introduction of a WT spr1178 allele restored the fitness of R6M1, although the growth defect could not be completely reverted (Figure $2 b)$.

\section{Discussion}

Whole genome sequencing of sensitive and resistant organisms is a powerful tool for understanding the biology of resistance mechanisms [18,19,25-27]. We sequenced two independent mutants selected for penicillin resistance in vitro to concentrate on recurrent mutations, a strategy proven to be useful [19]. Resistance to $\beta$-lactams in S. pneumoniae clinical isolates was shown to be a complex process involving the acquisition of PBP variants of low antibiotic affinity by intra- and interspecies gene transfer events from related streptococcal species $[4,5]$. Most PBP mutations directly involved in resistance were shown to alter the polarity and charge distribution around the catalytic cleft of the proteins. Indeed, the G552E substitution located in the vicinity of the active site of PBP2x [28] is a major determinant of $\beta$-lactam resistance [29-31] by inducing a decreased acylation efficiency to the protein [31]. Interestingly, several PBP2x mutations have been selected in our R6 and 1974 penicillin-resistant mutants, with every resistant strain except for R6M2 having acquired the Q552E substitution (Table 3). Other PBP2x mutations that have been specifically selected in at least one of our mutants include the $\mathrm{A} 369 \mathrm{~V}$ substitution in R6M2 that was previously reported to be one of the six PBP2x mutations responsible for the $\beta$-lactam resistance of $S$. pneumoniae clinical isolates [32] and the G601V 

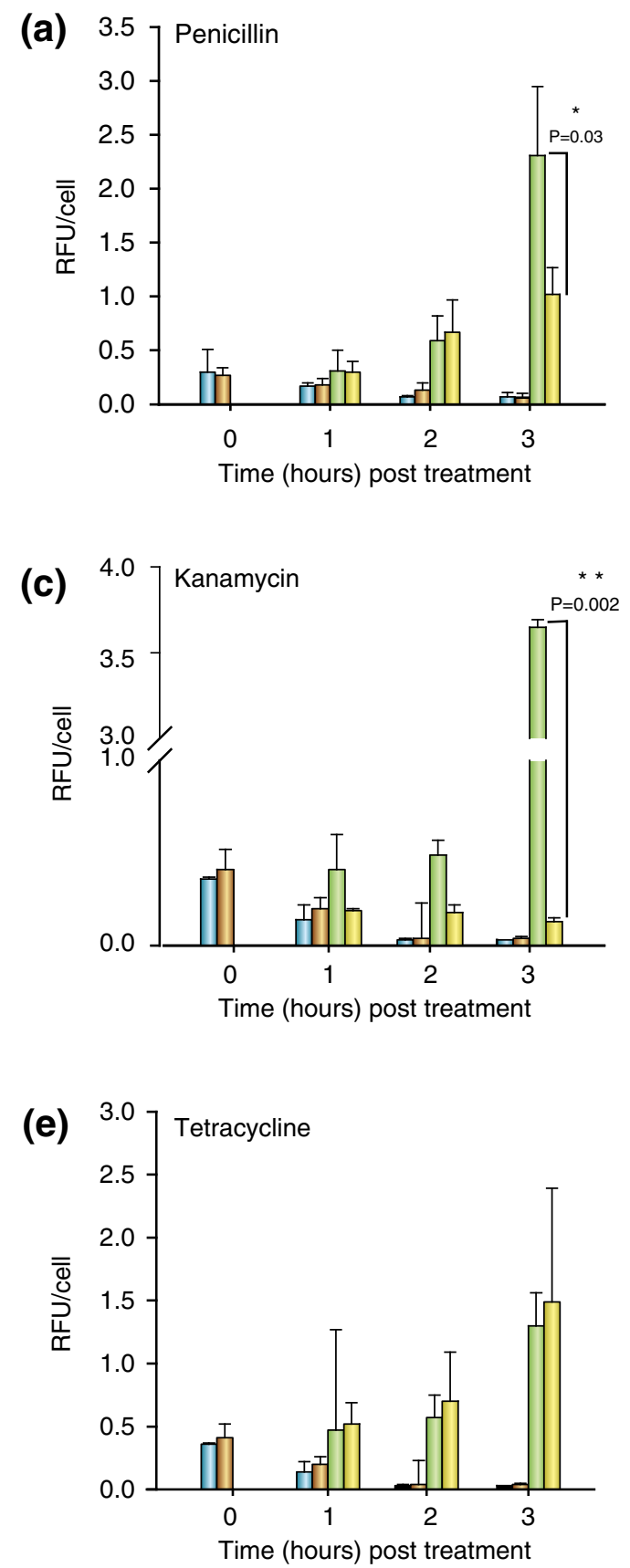
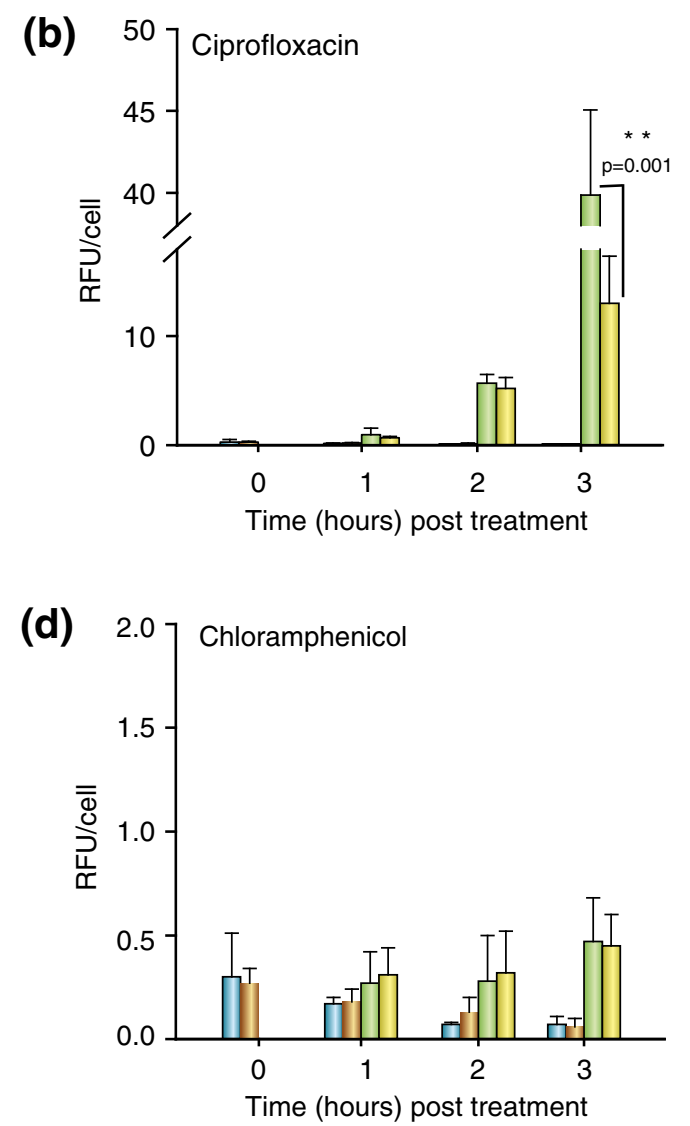

Figure 1 Nonsense mutation in spr1178 and reduced accumulation of reactive oxygen species induced by bactericidal antibiotics Drug-induced reactive oxygen species accumulation in S. pneumoniae. The DCF-DA fluorescence signals of the S. pneumoniae R6 $6^{\mathrm{SmR}, 2 \times 2 \mathrm{~b} 1 \mathrm{a}-\mathrm{M} 2}$

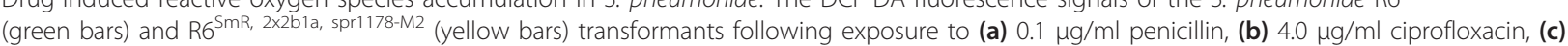
$400.0 \mathrm{\mu g} / \mathrm{ml}$ kanamycin, (d) $6.0 \mathrm{\mu g} / \mathrm{ml}$ chloramphenicol, and (e) $0.25 \mathrm{\mu g} / \mathrm{ml}$ tetracycline were measured prior to antibiotic exposure (time zero) and 1 hour, 2 hours, and 3 hours following addition of the antibiotics. The DCF-DA fluorescence signals of the S. pneumoniae R6 $6^{\mathrm{SmR}, 2 \times 2 \mathrm{~b} l \mathrm{a}-\mathrm{M} 2}$

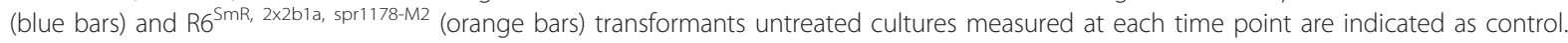
Results are the average of at least three independent experiments. RFU, relative fluorescence units.

substitution observed in 1974M1 that was shown to indirectly affect the active site of PBP2x by introducing a bulkier side chain involved in topological alterations of the catalytic cleft [8]. The F388L substitution selected in
1974M1 was shown to be one of the three substitutions responsible for cefotaxime resistance in a S. pneumoniae clinical isolate [8]. The F388L substitution is in the core of a hydrophobic niche close to the catalytic serine, 

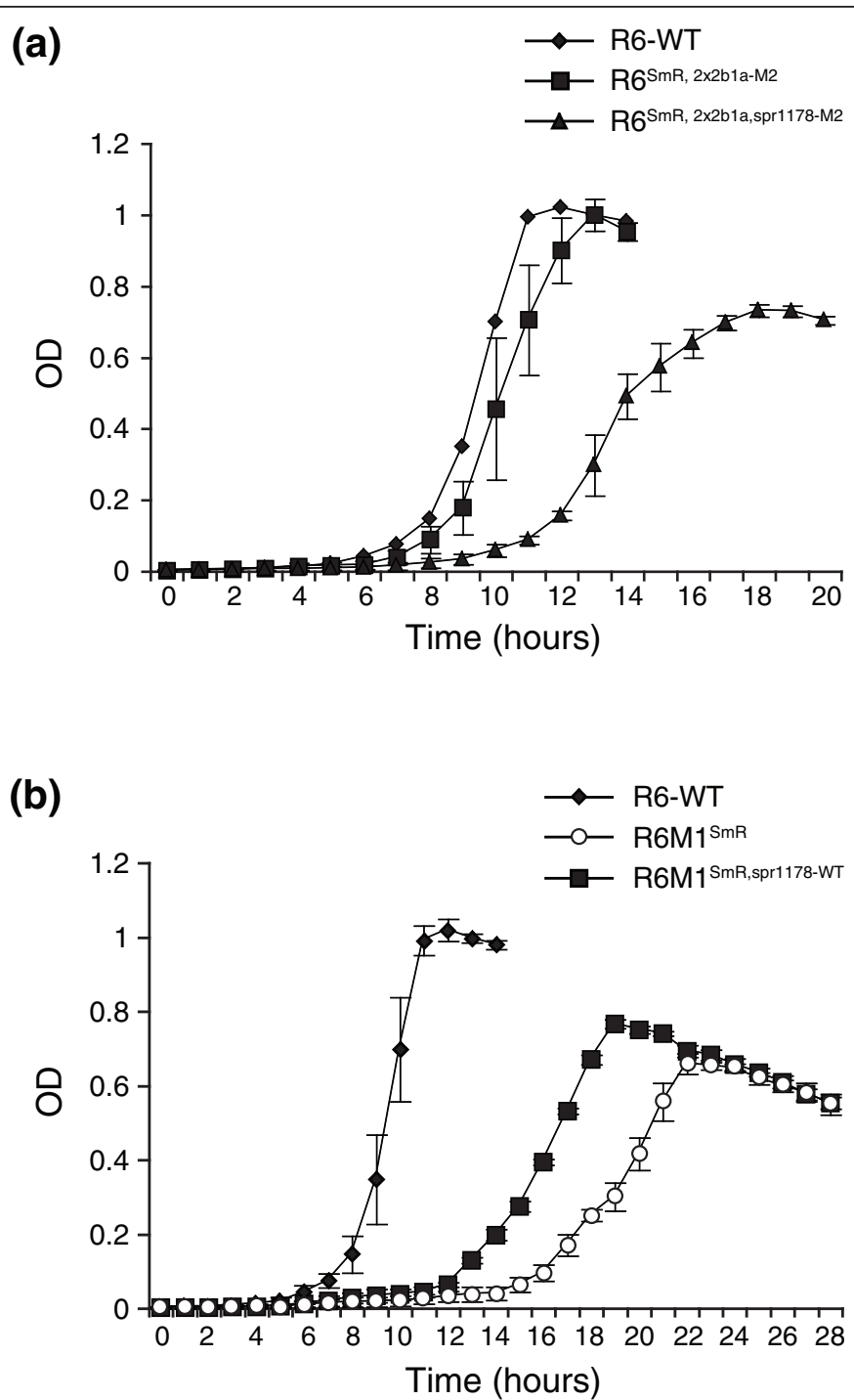

Figure 2 Nonsense mutation in spr1178 and growth defect in penicillin-resistant S. pneumoniae. (a) The growth kinetics of S. pneumoniae

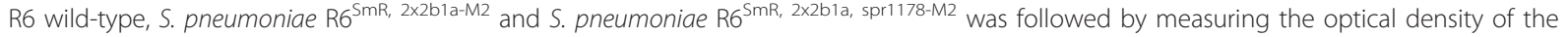
cultures every hour for a 20-hour period. (b) The reversion of the spr1178 nonsense mutation to a wild-type sequence decreased the growth defect of the R6M1 mutant. Results are the average of at least three independent measurements.

along with the adjacent S389L change frequently observed in resistant isolates [29], and could be involved in conformational alterations of the catalytic cleft. Finally, other PBP2x mutations identified in our penicillin-resistant strains probably have more indirect roles in resistance, like the R384G and R426C substitutions selected in both R6 mutants. These substitutions have also been found in a previously described series of laboratory-derived cefotaxime-resistant mutants [33].

Reconstruction of resistance by the stepwise introduction of PBP mutations into a R6 penicillin susceptible background revealed an ordered appearance of mutations first in $p b p 2 x$, then in $p b p 2 b$ and finally in $p b p 1 a$. Although the R426C and V518I substitutions in PBP2x only appeared at the third and fifth level of R6M2 selection (Additional file 2), transformation experiments failed at introducing these PBP2x substitutions. The R426C substitution was previously suggested to act as a compensatory mutation that requires a specific genetic background in order to be effective [8], which could provide a plausible explanation to our failure to transfer this mutation into the $\mathrm{R}^{2 \mathrm{x}-\mathrm{M} 2}$ transformant. PBP1a variants have been previously shown to confer high-level penicillin resistance only in the presence of low affinity PBP2x [34,35] and/or PBP2b [35]. In our study, however, the introduction of the PBP1a nonsense mutation from $\mathrm{R} 6 \mathrm{M} 2$ into the $\mathrm{R} 6^{2 \times 2 \mathrm{~b}-\mathrm{M} 2}$ line failed to increase the level of resistance to penicillin. It also appeared that a 
specific PBP-unrelated genetic background is required for PBP1a to participate in resistance as the reversion of its mutation in R6M1 resulted in a twofold decrease in resistance (Table 4).

In previously characterized laboratory-derived penicillin and cefotaxime-resistant mutants [36], PBP variants associated with resistance occurred late during the selection process $[37,38]$, suggesting that the initial increase in resistance during the first steps of selection involves non-PBP mutations. Similarly, the transfer of R6M2 PBP mutations to a penicillin-susceptible strain did not allow it to reach the resistance level of the parent mutant R6M2. Together, this implies that other mutations are probably involved in resistance. The analysis for recurrent mutations in our panel of resistant strains pinpointed a nonsense mutation in the putative iron permease spr1178 that occurred early during the selection process, before any PBP mutations could be selected (with the exception of the Q281P substitution in R6M2) (Additional file 2). It has recently been argued that bactericidal antibiotics, regardless of their primary targets, kill bacteria by inducing alterations in iron homeostasis, ultimately leading to the accumulation of hydroxyl radicals through the Fenton reaction [24]. Signaling events implicating the envelope stress-response and redox-responsive two-component systems were also found to be key players in triggering hydroxyl radical formation [39]. Although iron-sulfur clusters were initially implicated as the source of iron [24,40], the inactivation of TonB in Escherichia coli revealed that exogenous iron can also be implicated in the hydroxyurea-induced accumulation of ROS [41]. In this study, we have shown that three classes of bactericidal drugs, penicillin, ciprofloxacin and kanamycin, stimulate a greater production of ROS in the presence of a functional version of spr1178. Bacteriostatic antibiotics like tetracycline and chloramphenicol failed to induce ROS irrespective of the functional status of spr1178. Even though the transformation of the spr1178 nonsense mutation under a background of mutated PBPs did not reveal a direct role in resistance to penicillin, its early inactivation could have provided increased protection against the accumulation of ROS during the selection of resistance by potentially decreasing the availability of free iron. Moreover, the R6M2 mutant further harbors a nonsense mutation in another putative iron uptake system (spr0934; Table 2), which could potentiate the protective effect conferred by the spr1178 inactivation. The analysis of a panel of five penicillin non-susceptible clinical isolates failed to show similar nonsense mutations in spr1178 (data not shown), but this might in part be explained by the obvious growth defect associated with the acquisition of this mutation (Figure 2). It is salient to point out that the exposure to sublethal concentrations of bactericidal antibiotics was shown to induce a decreased expression of iron uptake systems in Pseudomonas aeruginosa [42] and S. pneumoniae [37], so similar gene expression alterations could also potentially occur in clinical isolates to prevent the accumulation of ROS during the early steps of resistance selection, instead of more drastic events like nonsense mutation as observed in isolates selected in vitro.

Our comparative genomic approach revealed that the selection for penicillin resistance in S. pneumoniae frequently involves the acquisition of a nonsense mutation in a putative iron transport system that increases the tolerance to antibiotic-induced accumulation of ROS. This tolerance should lead to an increased survival that putatively allows the selection of more important resistance determinants, such as the sequential accumulation of point mutations in PBPs.

\section{Conclusions}

This study indicates that, for in vitro isolates, mutations in PBPs are not sufficient to achieve high level resistance to penicillin. Our study also reveals that penicillin kills cells by producing ROS, possibly through the Fenton reaction since less ROS are produced in resistant mutants in which a putative iron transporter is mutated. The whole genome sequencing data further revealed other mutations that were acquired by at least one mutant and we propose that some of these, or a combination of mutations, could be associated with penicillin resistance along with mutations in PBPs.

\section{Materials and methods}

\section{Bacterial strains and culture conditions}

All strains used in this study are listed in Table 4. Pneumoccoci were grown as previously described [19]. Clones of the S. pneumoniae R6 laboratory strain and the clinical isolate S. pneumoniae CCRI-1974 [19] were used for the laboratory-induced selection of penicillin resistance. The selection of resistance was performed on Zybalski plates containing concentration gradients of PG as described previously for other drugs [43]. For subculturing, colonies were picked in the area of highest antibiotic concentrations and streaked onto agar plates containing either the same concentration of antibiotic or a gradient of increased antibiotic concentrations. The MIC of the resistant cells isolated from the plates with the highest concentrations of antibiotic was determined to confirm the resistance phenotype. Five selection cycles were required to obtain the highly resistant M1 and M2 mutants for each strain.

\section{Antibiotic susceptibility}

Antibiotic susceptibilities were determined with E-test strips (AB bioMérieux, Stockholm, Sweden) on Müller- 
Hinton agar plates supplemented with 5\% sheep blood using the manufacturer's instructions. The MICs were further confirmed by the microdilution method according to the Clinical Laboratory Standards Institute (CLSI) guidelines.

\section{Whole genome sequencing}

Genomic DNAs were prepared from mid-log phase $S$. pneumoniae cultures using the Wizard Genomic DNA Purification kit (Promega, Madison, WI, USA) according to the manufacturer's instructions. The genome of the R6M1 mutant was sequenced by using the NimbleGen WGS approach [44]. Briefly, DNA from the R6M1 mutant and its progenitor were differentially labeled with fluorescent markers and were co-hybridized on DNA tiling microarrays. Regions hybridizing differently were sequenced by a second round of sequencing hybridization arrays. The sequencing and analysis were performed by NimbleGen [20]. The genome of the R6M2 mutant was sequenced using the 454 Life Sciences (Roche, Branford, FL, USA) GS-FLX system. The genome sequencing, assemblies, and comparative analysis were performed at the McGill University Genome Quebec Innovation Center. The sequence of R6M2 is available at NCBI under the accession number PRJNA73471. Mutations, deduced from either array hybridizations or massively parallel sequencing, were confirmed by PCR amplification and Sanger sequencing. A circular map of the genome of R6M1 and R6M2 showing the identified mutations is provided (Additional file 1).

\section{DNA constructs}

The genetic constructs used in this study are described in Additional file 5. Gene inactivation was done by insertional duplication mutagenesis using the nonreplicative pFF3 and pFF6 plasmids. The pFF3 plasmid is a pGEMT easy (Promega) derivative into which an Eam1105I restriction site was introduced in the multiple cloning site and the ampicillin resistance marker was replaced by the chloramphenicol resistance marker of pEVP3 [45] (a kind gift of D Morrison, University of Illinois at Chicago). The pFF6 plasmid is a derivative of pFF3 in which the chloramphenicol resistance marker was replaced by the kanamycin marker of pDL289 [46] (a kind gift of D Cvitkovitch, University of Toronto). Fragments of the genes to be inactivated were amplified from genomic DNA of S. pneumoniae R6 (Additional file 4) and cloned into the multiple cloning sites of pFF3 or pFF6. The Janus cassette (a kind gift from D Morrison, University of Illinois, Chicago) was also used for gene inactivation and gene replacement study in a streptomycin-resistant background in S. pneumoniae as described [21]. Janus is a 1.3-kb cassette with a kanamycin resistance marker and a counterselectable rps $L$ marker conferring streptomycin sensitivity. To generate a streptomycin-resistant background, S. pneumoniae strains were transformed with a $r p s L^{+}$PCR fragment that was amplified from chromosomal DNA of the streptomycin-resistant strain CP1296 and the selection was done on agar supplemented with $150 \mu \mathrm{g} / \mathrm{ml}$ of streptomycin.

\section{Genetic transformation}

The penicillin-resistance phenotype was reconstructed by transforming the penicillin-susceptible $S$. pneumoniae R6 with PCR fragments amplified from the penicillinresistant R6M1 or R6M2 mutants (Additional file 4). Selection was done on plates containing appropriate concentrations of penicillin. Competent cells were obtained by the dilution of an overnight $S$. pneumoniae culture 1:100 in C+Y medium, pH 6.8 [47]. The diluted cultures were grown up to the onset of exponential phase before being concentrated ten times and frozen in $\mathrm{C}+\mathrm{Y}, \mathrm{pH}$ 6.8, 15\% glycerol. For transformation, competent cells were thawed on ice, diluted ten times with $\mathrm{C}$ $+\mathrm{Y}$ medium, $\mathrm{pH} 7.8$, and complemented with $2 \mu \mathrm{g} / \mathrm{ml}$ of competence stimulating peptide 1 (csp-1) before being incubated for 15 minutes at $35^{\circ} \mathrm{C}$ under a $5 \% \mathrm{CO}_{2}$ atmosphere. DNA was added to a final concentration of $2 \mu \mathrm{g} / \mathrm{ml}$ and the cultures were incubated for 1 hour at $30^{\circ} \mathrm{C}$. Finally, the cultures were switched to $35^{\circ} \mathrm{C}$ under a $5 \% \mathrm{CO}_{2}$ atmosphere for 1 hour before being plated on CAT medium containing the appropriate concentration of antibiotic. The plates were incubated for 48 hours at $35^{\circ} \mathrm{C}$ under a $5 \% \mathrm{CO}_{2}$ atmosphere and the resistant colonies were picked for further studies.

\section{Detection of reactive oxygen species}

The intracellular ROS accumulation was measured using the DCF-DA dye (Invitrogen, Grand Island, NY, USA) whose fluorescence is proportional to the level of ROS [48]. In a typical experiment, cells were grown to the onset of exponential phase $\left(\mathrm{OD}_{600} 0.12\right)$ before penicillin, ciprofloxacin, kanamycin, chloramphenicol or tetracycline were added at a final concentration of $0.1,4.0$, 400, 6.0 and $0.25 \mu \mathrm{g} / \mathrm{ml}$, respectively. One milliliter aliquots were collected at baseline (prior to the addition of antibiotic) and at 1,2 and 3 hours following the addition of antibiotic. The aliquots were washed once and resuspended in $500 \mu \mathrm{l}$ of $1 \times \mathrm{PBS}(\mathrm{pH} 7.2)$ containing 5 $\mu \mathrm{M}$ DCF-DA and incubated at $37^{\circ} \mathrm{C}$ in the dark for 30 minutes. The labeled cells were washed once and resuspended in $500 \mu \mathrm{l}$ of $1 \times$ PBS. The fluorescence signal of a $200 \mu \mathrm{l}$ aliquot was analyzed using a Victor fluorometer (Perkin-Elmer, Waltham, MA, USA) at $485 \mathrm{~nm}$ excitation and $535 \mathrm{~nm}$ emission wavelengths. Results are expressed as relative fluorescence units (RFU) and were normalized according to the number of live cells at each 
time point. A minimum of three independent experiments have been performed for each antibiotic.

\section{Additional material}

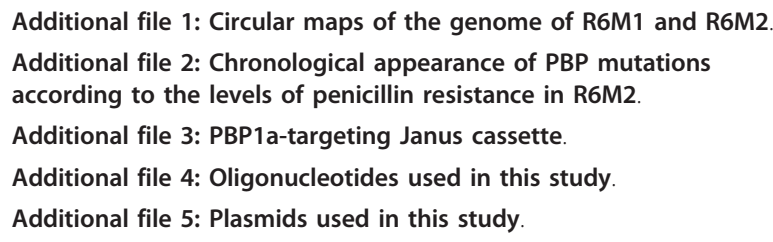

\section{Abbreviations}

DCF-DA: dichlorofluorescein diacetate; MIC: minimum inhibitory concentration; PBP: penicillin-binding protein; PBS: phosphate-buffered saline; PCR: polymerase chain reaction; PG: penicillin G; ROS: reactive oxygen species; SNP: single-nucleotide polymorphism; WGS: whole genome sequencing; WT: wild-type.

\section{Acknowledgements}

We thank Dr D Morrison (Chicago) for the Janus cassette. This work was funded by a CIHR grant to MO. FF received a studentship from the Fondation de I'Université Laval and MO holds the Canada Research Chair in Antimicrobial Resistance. We thank the McGill University Genome Quebec Innovation Centre for performing the sequencing.

\section{Authors' contributions}

FF, DL and MO designed the study. FF performed the experiments, analyzed the data and drafted the manuscript; PL and DL revised the manuscript and provided critical comments. All authors approved the final version of the manuscript.

\section{Competing interests}

The authors declare that they have no competing interests.

Received: 10 July 2011 Revised: 29 September 2011

Accepted: 22 November 2011 Published: 22 November 2011

\section{References}

1. Klugman KP, Feldman C: Streptococcus pneumoniae respiratory tract infections. Curr Opin Infect Dis 2001, 14:173-179.

2. Linares J, Ardanuy C, Pallares R, Fenoll A: Changes in antimicrobial resistance, serotypes and genotypes in Streptococcus pneumoniae over a 30-year period. Clin Microbiol Infect 2010, 16:402-410.

3. Zhanel GG, Karlowsky JA, Palatnick L, Vercaigne L, Low DE, Hoban DJ: Prevalence of antimicrobial resistance in respiratory tract isolates of Streptococcus pneumoniae: results of a Canadian national surveillance study. The Canadian Respiratory Infection Study Group. Antimicrob Agents Chemother 1999, 43:2504-2509.

4. Hakenbeck R, Grebe T, Zahner D, Stock JB: beta-lactam resistance in Streptococcus pneumoniae: penicillin-binding proteins and nonpenicillin-binding proteins. Mol Microbiol 1999, 33:673-678.

5. Chambers HF: Penicillin-binding protein-mediated resistance in pneumococci and staphylococci. J Infect Dis 1999, 179(Suppl 2):S353-359.

6. Smith AM, Klugman KP: Alterations in PBP 1A essential-for high-level penicillin resistance in Streptococcus pneumoniae. Antimicrob Agents Chemother 1998, 42:1329-1333.

7. du Plessis M, Bingen E, Klugman KP: Analysis of penicillin-binding protein genes of clinical isolates of Streptococcus pneumoniae with reduced susceptibility to amoxicillin. Antimicrob Agents Chemother 2002, 46:2349-2357.

8. Maurer $\mathrm{P}$, Koch B, Zerfass I, Krauss J, van der Linden M, Frere JM, ContrerasMartel C, Hakenbeck R: Penicillin-binding protein 2x of Streptococcus pneumoniae: three new mutational pathways for remodelling an essential enzyme into a resistance determinant. J Mol Biol 2008, 376:1403-1416.

9. Izdebski R, Rutschmann J, Fiett J, Sadowy E, Gniadkowski M, Hryniewicz W, Hakenbeck R: Highly variable penicillin resistance determinants PBP $2 x$, PBP 2b, and PBP 1a in isolates of two Streptococcus pneumoniae clonal groups, Poland 23F-16 and Poland 6B-20. Antimicrob Agents Chemother 2008, 52:1021-1027.

10. Filipe SR, Tomasz A: Inhibition of the expression of penicillin resistance in Streptococcus pneumoniae by inactivation of cell wall muropeptide branching genes. Proc Natl Acad Sci USA 2000, 97:4891-4896.

11. Smith AM, Klugman KP: Alterations in MurM, a cell wall muropeptide branching enzyme, increase high-level penicillin and cephalosporin resistance in Streptococcus pneumoniae. Antimicrob Agents Chemother 2001, 45:2393-2396.

12. Tait-Kamradt AG, Cronan M, Dougherty TJ: Comparative genome analysis of high-level penicillin resistance in Streptococcus pneumoniae. Microb Drug Resist 2009, 15:69-75.

13. Crisostomo MI, Vollmer W, Kharat AS, Inhulsen S, Gehre F, Buckenmaier S, Tomasz A: Attenuation of penicillin resistance in a peptidoglycan Oacetyl transferase mutant of Streptococcus pneumoniae. Mol Microbiol 2006, 61:1497-1509.

14. Grebe T, Hakenbeck R: Penicillin-binding proteins $2 b$ and $2 x$ of Streptococcus pneumoniae are primary resistance determinants for different classes of beta-lactam antibiotics. Antimicrob Agents Chemother 1996, 40:829-834.

15. Dias R, Felix D, Canica M, Trombe MC: The highly conserved serine threonine kinase StkP of Streptococcus pneumoniae contributes to penicillin susceptibility independently from genes encoding penicillinbinding proteins. BMC Microbiol 2009, 9:121

16. Guenzi E, Gasc AM, Sicard MA, Hakenbeck R: A two-component signaltransducing system is involved in competence and penicillin susceptibility in laboratory mutants of Streptococcus pneumoniae. Mol Microbiol 1994, 12:505-515.

17. Soualhine H, Brochu V, Menard F, Papadopoulou B, Weiss K, Bergeron MG, Legare D, Drummelsmith J, Ouellette M: A proteomic analysis of penicillin resistance in Streptococcus pneumoniae reveals a novel role for PstS, a subunit of the phosphate ABC transporter. Mol Microbiol 2005, 58:1430-1440.

18. Mwangi MM, Wu SW, Zhou Y, Sieradzki K, de Lencastre $H$, Richardson $P$, Bruce D, Rubin E, Myers E, Siggia ED, Tomasz A: Tracking the in vivo evolution of multidrug resistance in Staphylococcus aureus by wholegenome sequencing. Proc Natl Acad Sci USA 2007, 104:9451-9456.

19. Feng J, Lupien A, Gingras H, Wasserscheid J, Dewar K, Legare D, Ouellette M: Genome sequencing of linezolid-resistant Streptococcus pneumoniae mutants reveals novel mechanisms of resistance. Genome Res 2009, 19:1214-1223.

20. Albert TJ, Dailidiene D, Dailide G, Norton JE, Kalia A, Richmond TA, Molla M, Singh J, Green RD, Berg DE: Mutation discovery in bacterial genomes: metronidazole resistance in Helicobacter pylori. Nat Methods 2005, 2:951-953.

21. Sung CK, Li H, Claverys JP, Morrison DA: An rpsL cassette, janus, for gene replacement through negative selection in Streptococcus pneumoniae. Appl Environ Microbiol 2001, 67:5190-5196.

22. Stearman R, Yuan DS, Yamaguchi-Iwai Y, Klausner RD, Dancis A: A permease-oxidase complex involved in high-affinity iron uptake in yeast. Science 1996, 271:1552-1557.

23. Vickerman MM, lobst S, Jesionowski AM, Gill SR: Genome-wide transcriptional changes in Streptococcus gordonii in response to competence signaling peptide. J Bacteriol 2007, 189:7799-7807.

24. Kohanski MA, Dwyer DJ, Hayete B, Lawrence CA, Collins JJ: A common mechanism of cellular death induced by bactericidal antibiotics. Cell 2007, 130:797-810.

25. Howden BP, Stinear TP, Allen DL, Johnson PD, Ward PB, Davies JK: Genomic analysis reveals a point mutation in the two-component sensor gene graS that leads to intermediate vancomycin resistance in clinical Staphylococcus aureus. Antimicrob Agents Chemother 2008, 52:3755-3762.

26. Highlander SK, Hultén KG, Qin X, Jiang H, Yerrapragada S, Mason EO Jr, Shang $Y$, Williams TM, Fortunov RM, Liu Y, Igboeli O, Petrosino J, Tirumalai M, Uzman A, Fox GE, Cardenas AM, Muzny DM, Hemphill L, 
Ding Y, Dugan S, Blyth PR, Buhay CJ, Dinh HH, Hawes AC, Holder M, Kovar CL, Lee SL, Liu W, Nazareth LV, Wang Q, et al: Subtle genetic changes enhance virulence of methicillin resistant and sensitive Staphylococcus aureus. BMC Microbiol 2007, 7:99.

27. Cui L, Neoh HM, Shoji M, Hiramatsu K: Contribution of vraSR and graSR point mutations to vancomycin resistance in vancomycin-intermediate Staphylococcus aureus. Antimicrob Agents Chemother 2009, 53:1231-1234.

28. Chesnel L, Zapun A, Mouz N, Dideberg O, Vernet T: Increase of the deacylation rate of PBP2x from Streptococcus pneumoniae by single point mutations mimicking the class A beta-lactamases. Eur $\mathcal{B}$ Biochem 2002, 269:1678-1683.

29. Pernot L, Chesnel L, Le Gouellec A, Croize J, Vernet T, Dideberg O, Dessen A: A PBP2x from a clinical isolate of Streptococcus pneumoniae exhibits an alternative mechanism for reduction of susceptibility to beta-lactam antibiotics. J Biol Chem 2004, 279:16463-16470.

30. Mouz N, Gordon E, Di Guilmi AM, Petit I, Petillot Y, Dupont Y, Hakenbeck R, Vernet T, Dideberg O: Identification of a structural determinant for resistance to beta-lactam antibiotics in Gram-positive bacteria. Proc Natl Acad Sci USA 1998, 95:13403-13406.

31. Mouz N, Di Guilmi AM, Gordon E, Hakenbeck R, Dideberg O, Vernet T: Mutations in the active site of penicillin-binding protein PBP2x from Streptococcus pneumoniae. Role in the specificity for beta-lactam antibiotics. J Biol Chem 1999, 274:19175-19180.

32. Smith AM, Klugman KP: Amino acid mutations essential to production of an altered PBP $2 \mathrm{X}$ conferring high-level beta-lactam resistance in a clinical isolate of Streptococcus pneumoniae. Antimicrob Agents Chemother 2005, 49:4622-4627.

33. Laible G, Hakenbeck R: Penicillin-binding proteins in beta-lactam-resistant laboratory mutants of Streptococcus pneumoniae. Mol Microbiol 1987, 1:355-363.

34. Munoz R, Dowson CG, Daniels M, Coffey TJ, Martin C, Hakenbeck R, Spratt BG: Genetics of resistance to third-generation cephalosporins in clinical isolates of Streptococcus pneumoniae. Mol Microbiol 1992, 6:2461-2465.

35. Reichmann P, Konig A, Marton A, Hakenbeck R: Penicillin-binding proteins as resistance determinants in clinical isolates of Streptococcus pneumoniae. Microb Drug Resist 1996, 2:177-181.

36. Hakenbeck R, Martin C, Dowson C, Grebe T: Penicillin-binding protein $2 b$ of Streptococcus pneumoniae in piperacillin-resistant laboratory mutants. J Bacteriol 1994, 176:5574-5577.

37. Rogers PD, Liu TT, Barker KS, Hilliard GM, English BK, Thornton J, Swiatlo E, McDaniel LS: Gene expression profiling of the response of Streptococcus pneumoniae to penicillin. J Antimicrob Chemother 2007, 59:616-626.

38. Krauss J, van der Linden $M$, Grebe T, Hakenbeck R: Penicillin-binding proteins $2 \mathrm{x}$ and $2 \mathrm{~b}$ as primary PBP targets in Streptococcus pneumoniae. Microb Drug Resist 1996, 2:183-186.

39. Kohanski MA, Dwyer DJ, Wierzbowski J, Cottarel G, Collins JJ: Mistranslation of membrane proteins and two-component system activation trigger antibiotic-mediated cell death. Cell 2008, 135:679-690.

40. Dwyer DJ, Kohanski MA, Hayete B, Collins JJ: Gyrase inhibitors induce an oxidative damage cellular death pathway in Escherichia coli. Mol Syst Biol 2007, 3:91

41. Davies BW, Kohanski MA, Simmons LA, Winkler JA, Collins JJ, Walker GC: Hydroxyurea induces hydroxyl radical-mediated cell death in Escherichia coli. Mol Cell 2009, 36:845-860.

42. Mikkelsen H, Swatton JE, Lilley KS, Welch M: Proteomic analysis of the adaptive responses of Pseudomonas aeruginosa to aminoglycoside antibiotics. FEMS Microbiol Lett 2010.

43. Martineau F, Picard FJ, Lansac N, Menard C, Roy PH, Ouellette M, Bergeron MG: Correlation between the resistance genotype determined by multiplex PCR assays and the antibiotic susceptibility patterns of Staphylococcus aureus and Staphylococcus epidermidis. Antimicrob Agents Chemother 2000, 44:231-238.

44. Roche NimbleGen. [http://www.nimblegen.com]

45. Claverys JP, Dintilhac A, Pestova EV, Martin B, Morrison DA: Construction and evaluation of new drug-resistance cassettes for gene disruption mutagenesis in Streptococcus pneumoniae, using an ami test platform. Gene 1995, 164:123-128.

46. Buckley ND, Lee LN, LeBlanc DJ: Use of a novel mobilizable vector to inactivate the scrA gene of Streptococcus sobrinus by allelic replacement. J Bacteriol 1995, 177:5028-5034.
47. Tomasz A, Hotchkiss RD: Regulation of the transformability of pheumococcal cultures by macromolecular cell products. Proc Natl Acad Sci USA 1964, 51:480-487.

48. Moreira W, Leblanc E, Ouellette M: The role of reduced pterins in resistance to reactive oxygen and nitrogen intermediates in the protozoan parasite Leishmania. Free Radic Biol Med 2009, 46:367-375.

doi:10.1186/gb-2011-12-11-r115

Cite this article as: Fani et al:: Whole genome sequencing of penicillinresistant Streptococcus pneumoniae reveals mutations in penicillinbinding proteins and in a putative iron permease. Genome Biology 2011 12:R115.

\section{Submit your next manuscript to BioMed Central and take full advantage of:}

- Convenient online submission

- Thorough peer review

- No space constraints or color figure charges

- Immediate publication on acceptance

- Inclusion in PubMed, CAS, Scopus and Google Scholar

- Research which is freely available for redistribution

Submit your manuscript at www.biomedcentral.com/submit
Biomed Central 